\title{
Perception of demographic and cultural factors associated with the crime of human trafficking in Nigeria
}

\author{
Nwokeoma Bonaventure N \\ Department of Sociology and Anthropology, \\ University of Nigeria Nsukka \\ Email:Bonaventure.nwokeoma@unn.edu.ng
}

\begin{abstract}
Context/background:The demographic and cultural factors that drive the crime of human trafficking have not been properly researched in Nigeria. This study therefore examines the perception of the association between population characteristics, fertility norms and human trafficking.

Methods:This study used 600 respondents from Imo State. Data was collected through questionnaire and in-depth interviews from two local governments that are active sites for human trafficking. Descriptive statistics, chi-square and regression analysis were used to analyse the data.

Results:The findings showed a preponderance of females as victims and traffickers than males, with a significant relationship of $\mathrm{P}<0.00 \mathrm{I}$ between the sex of traffickers and human trafficking. The age group that are mostly trafficked are 16-25 years for women and 5-14 years for male and female children. Large family size driven by a traditional fertility rite (ewu- ukwu) for women with $10+$ children was found to be strongly associated with human trafficking.

Conclusion:The study recommends aggressive birth control program that targets traditional fertility norms and programs that offer livelihood options and increased well being for women.
\end{abstract}

Keywords: Demographic; Cultural; Factors; Perception; Human trafficking.

\section{Introduction}

Human trafficking is a global phenomenon. The crime has reached an epidemic proportion and has been found to exist in almost all parts of the World (Shelley 2010; Peters 20I5; Bales 20I2; CNN Freedom Project, 2018). Human trafficking is also prevalent in all countries although the general awareness and institutional actions toward combating the trend is low. (Shelley, 2010; Gallagher, 2013; Peters, 2015; Kara, 2017; Zimmerman and Kiss, 2017). According to the United Nations Office on Drugs and Crime (UNODC, 2004), human trafficking is prevalent in Africa and Asia, but growing fastest in Central and Eastern Europe. Analytically, the concept of human trafficking or trafficking in person has become so complex that an obvious challenge exists with regards to its definition and actual meanings. Indeed, the parameter around what constitutes human trafficking has been hotly contested. According to Coomaraswany (2000); Chi-Ying Chung (2006); Hume and Sidun (2016), there are various definitions of human trafficking, though the term has been used by different actors to describe activities that range from voluntary migration, the exploitation of prostitution, to the movement of persons through the threat or use of force, coercion or violence for certain exploitative purposes. Consequently, anti trafficking discourses establish regimes of knowledge that set boundaries for how scholars, activists, legislators, criminal justice actors and citizens conceive human trafficking. They establish what trafficking is, who count as trafficked and create narratives that explain how trafficking has become a problem and what should be done to fix it, which at least serves as a bench mark for analysis (Lobasz, 20I2).

Despite the dilemma surrounding the actual definition and meaning of human trafficking, this paper adopts the United Nations definition as the most internationally acceptable bench mark. Human trafficking is defined by the United Nations protocol as "the recruitment, transportation, transfer, harboring or receipt of person...for the purpose of exploitation..." (Zimmerman and Kiss, 2017; NAPTIP News, 2006:33). The International Labor Organization (ILO) also noted that for human movement to qualify as trafficking there should be the conclusion of a transaction, the intervention of an intermediary, and the motive to exploit. Human trafficking networks involve several processes, stages and diverse groups of persons from local pimps to foreign syndicates (Kara, 20I7; Bales, 20I2).

According to a UNODC (2018) document, human trafficking is a complex phenomenon that is often 
driven by social, economic, cultural and other factors which are specific to different trafficking patterns and to the states in which they occur. Shelley $(2010)$ identified three demographic forces which have contributed to human trafficking. These are population growth, especially in the developing world; the increasing imbalance between men and women and rural urban migration. However, Ngbani, Maliki and Asuquo (2017) in a study conducted with 1000 respondents in South South region of Nigeria, rather than generally focus on population growth, examined how specific demographic variables like age, gender and residential location influence the perception of human trafficking. The results showed significant positive relationship between the independent and dependent variables. According to Hepburn and Simon (2013), cultural norms and biases, societal assumptions and conflicting policies make trafficking scenarios so pervasive and resilience. Bryant-Davis and Tummala-Nara (2016) also observed that human trafficking is maintained within a context of intersecting forms of cultural oppression which generate unique challenges for prevention and intervention. Crawford (2016) further observed that although international sex trafficking is often attributed to poverty and under development, it is mostly fostered by a more complex matrix of economic and cultural factors. In a study on Asia, ChYin Chung (2006) also stated that Asian girls are especially vulnerable to trafficking due to traditional Asian cultural and social values.

\section{Statement of the problem}

Human trafficking has been identified by nations and international agencies as a global problem which is akin to modern day slavery. The United States Department of State (USDS) estimates that between 800,000 - 900,000 people are trafficked across international borders annually, (USDS Report, 2003, Pierpaolo, 2003). According to Angeli (2003) every year, about 700,000 people mainly women and children are traded by criminal organizations. Macheto (2005) also states that the International Labor Organization, (ILO) estimates that 12.3 million people are enslaved in forced and bonded labor, and about 2.4 million of these are victims of trafficking. The United Nations International Children Education Fund (UNICEF) also estimated that more than 200,000 children are trafficked in West and Central Africa, (UNODC, 2005). Though these figures are mostly official statistics that are not necessarily derived from empirical studies, they definitely underscore the global enormity and challenge posed by the practice of human trafficking.

According to the United States Department of States Report, (2004), Nigeria is a source, transit and destination country for trafficking in women and children. Nigerians are trafficked to Europe, especially Italy, Spain, France, Netherlands, UK and America (Pearson, 2003). Some are also trafficked to Saudi Arabia and Egypt, while others are trafficked to African countries like South Africa, Morocco, Gabon, Libya, Cameroon Equatorial Guinea etc. UNICEF Fact sheet (2002) also stated that $43 \%$ of about 8 million Nigerian children engaged in exploitative child labour and who are at the risk of being trafficked are based in Calabar, Port-Harcourt and Owerri in Imo State. Aransiola and Zarowsky, (20/4) in a study on street children and human trafficking in Lagos, Kaduna and Port Harcourt, also confirmed the trafficking, exploitation and abuse of street children in Nigeria. Findings by the Imo State government in 200I revealed that human trafficking is predominant within Mbaise, Mbano and Ohaji areas of the state. According to Karlson, (2003:II) "Trafficking in persons is a cruel, ruthless, and cynical form of human exploitation, a serious crime and a gross violation of human dignity..." Human trafficking impedes and militates against the realization of the various principles of the Sustainable Development Goals (SDG's). Trafficking in human beings no doubt is a complex multi-layered problem. However, UNODC, (2005) and Laczkoy and Gozdziak (2005) noted that there is a lack of systematic research and reliable data on trafficking based on extensive fieldwork. Therefore, this study has set out to identify and analyze the demographic and cultural factors that precipitate and sustain the practice of human trafficking in Imo State Nigeria and to establish how the practice impedes and stunt the realization of the Sustainable Development Goals.

The study was guided by the following research questions:

(I) What is the level of awareness of human trafficking in Imo State?

(2) What demographic factors are associated with human trafficking in Imo State?

(3) What cultural factors are associated with human trafficking in Imo State?

(4) How does the practice of human trafficking affect the realization of the Sustainable Development Goals (SDGs)?

\section{Theoretical framework}

\section{Routine activities theory (RAT)}

The theoretical framework for this study is the routine activity theory. According to Schaefer (2005), this is a more recent interactionist explanation of criminal behavior which focuses on the requisite conditions that must be present for a criminal act to occur. Advocate of this theory like Felson, (2002) observed that for a criminal act to occur, there must 
be at the same time and in the same place a perpetrator, a victim, and an object. According to him, the convergence of motivated offenders and suitable targets creates a crime event. For instance, there can be no car theft without automobiles. Also, there can be no human trafficking without vulnerable individuals. The term "routine" suggests that the elements of a criminal or deviant act come together within the context of normal acceptable routine activity. Therefore, changes in the routine activities of individuals could lead to an increase or decrease in criminal behavior. Scholars like Sherman, Gartin and Buerger (1989) carried out some studies to show that certain crimes occur and also increased as individuals become more vulnerable.

Relating this theory to human trafficking, it could be said that the availability of vulnerable individuals mostly women and children, and the presence of motivated offenders leads to the prevalence of human trafficking. However, despite the relevance of this theory, it is important to note that the availability of vulnerable individuals and motivated offenders alone may not be sufficient for crime to occur, there has to be a conducive or permissive environment.

\section{Research hypotheses}

The following are the hypotheses for this study:

(I) Victims of human trafficking in Nigeria are most likely to be females than males.

(2) There is a positive relationship between large family size and being victim of human trafficking in Imo state, Nigeria

\section{Area of study}

The area of study for this research is Imo State of Nigeria. The choice of this area is significant and based on prior empirical findings. Data generated by UNICEF, (2000), Immigration update (2002), and NAPTIP, (2006), identified Imo state as one of the focal states for human trafficking in Nigeria.

Previous studies also corroborate this view. Pearson (2003:I) and Prina, (2003:I72) confirm that "many of the women trafficked to Europe are from the south east of Nigeria in particular the lbo tribes". Imo State is one of the Southeastern States and earned the present status of a state in 1991. The preoccupation of the people is agriculture and civil service. Mbano and Mbaise areas of the state engage mainly in subsistence cultivation of cassava, yam, palm products, etc. They also depend mostly on wage labor and with the abject lack of employment in the public service, the area experiences high unemployment rate.

\section{Methodology}

\section{Research design}

The study adopted a cross sectional survey design which is a design that enables a researcher to collect and analyze data from a representative subset of the universe at a specific point in time. (Obikeze, 1990; Babbie, 1992). The survey design is most amenable for this research because it is flexible and most suitable for obtaining data from large populations.

\section{Study population}

Imo State has a population of 3,927,563 million people, (NPC 2006 Census). In Imo State, Ahiazu Mbaise and Ehime - Mbano local governments were selected as the population of study. By the 2006 population census, the population of Ahiazu- Mbaise was 170,824 people, and the population of EhimeMbano was 130,575 people (NPC, 2006 Census). However this population is approximated to 2017 using the official Nigerian population growth rate of $3 \%$ which gives a population of 227, 188 for AhiazuMbaise and 173,662 for Ehime-Mbano. The selection of the local governments were based on the findings of previous studies which established them as high prevalent areas for trafficking in persons in Imo State. The actual population of the study will be made up of people from 15 years and above.

\section{Sample size}

The population of Imo State from I5years and above is $64 \%$ and the population of both local governments within this category is 400,850 . Therefore, a sample fraction of $0.1 \%$ was used to derive the sample size (Obikeze, 1986), which constitutes 400 . This number is however approximated to 600 respondents for ease of calculations and distribution of the research instruments. This population is consequently adopted as the sample size for this research.

\section{Sampling procedure}

The multistage cluster design was adopted for the research. Also, the random sampling process was applied to achieve the required sample size. The multistage design is very relevant because our study area is large and made up of several clusters like towns, villages and households. Therefore, we proceeded through the following stages to derive the stipulated sample size;

- Identification of towns

- Selection of villages

- Selection of households

- Selection of respondents 


\section{Identification of towns/communities}

In Imo state, three hundred (300) respondents were selected from each of the two local government areas. In each of the local governments, 7 towns/communities were identified.

\section{Selection of villages}

All the villages, areas in the towns and communities were listed and numbers assigned to them. The listed villages and areas were put into a basket and properly shuffled. There were a total number of 14 towns/communities. Then 5 villages were drawn from each of the towns or areas using a fixed sampling gap of one in two $(1: 2)$. The process is carried out without replacement, $14 \times 5=70$. The total numbers of villages listed were 165 .

\section{Selection of households}

The households in the 70 selected villages were also listed. They were assigned numbers, and put into a basket. The content of the basket was properly shuffled and 2 households each were selected, also using a fixed sampling gap of one in two (I:2), $2 \times 70$ $=140$. The total number of household listed were 2 , 260.

\section{Selection of respondents}

In each of the selected households, all the persons from 15 years and above were properly listed. Through a similar random process as above, we selected 2 respondents each from the first 120 households $=240$, and 3 persons were selected from the remaining 20 households $=60$ using a fixed sampling gap of one in two $(1: 2)$. Also, the process was carried out without replacement. This finally gave us a total of 300 respondents from each of the two local governments. Therefore, the total sample from the two local governments is $300 \times 2=600$. In Ehime Mbano, the distribution of the research instrument to Nsu, Umunumo and Nzerem started from Orieagu market centre while the distribution in Ehime started from Aba branch (Umuezeala Owerre) to Umunakanu, Umueze (towns in the area) and others. In Ahiazu Mbaise, the distribution started from Ogbe Ahiara. From there, the research assistants had access to Ogbe, Otulu, Oru, Ahiara, Nnarambia, Ekwereazu ( towns in the area)and other areas.

\section{Instruments for data collection}

The primary instrument used for the collection of data in this research is the questionnaire and In-depth interviews (IDI). The questionnaire contained approximately 40 sets of uniform questions. This was administered to the 600 selected respondents from the age of 15 and above who attained the minimum of primary school education. The questionnaire was self administered, and a total of 600 questionnaire were administered. However, 570 questionnaire were eventually collected and returned. This gave us a response rate (RR) of $95 \%$. The research instruments were pretested in Ihitte and Obowo areas. Qualitative data were obtained through indepth interview with 28 purposively selected respondents including 10 victims, 8commuinty leaders, 4 officers each from Immigration and NAPTIP and 2 personnel of women affairs commission. They were purposively selected on the basis of their professions, experience and knowledge.

\section{Method of data analysis}

Data were analyzed through the deductive approach. Descriptive statistics like percentages, statistical tables, graphics illustrations were used to describe the relationship between vital variables. The data from the questionnaire was processed and analyzed using EPI version 6 and the statistical package for the social sciences (SPSS). Relevant test statistic like the chi-square $\left(x^{2}\right)$ and multiple regression analysis was also applied.

\section{Results and analysis}

The sample was evenly distributed in the two selected L.G.A's in the state at three hundred respondents each, however, the response pattern shows that in Ehime-Mbano L.G.A, two hundred and ninety (290) while in Ahiazu-Mbaise, two hundred and eighty (280) were returned. Generally, 570 respondents were used for this study, and this gave a response rate of $95 \%$.

\section{Socio demographic characteristics of respondents} Sex distribution of respondents

From a total of five hundred and seventy (570) respondents used in this study, two hundred and thirty, (42\%) were males and three hundred and forty, (58\%) were females. The gender distribution of the respondents showed that in Ehime-Mbano, the males were less than half $(42 \%)$ while the females were more than half $(58 \%)$ of the respondents. In Ahiazu-Mbaise while the male constitute less than one-third (40.4\%), the females constitute almost two-third (58.6\%) of the respondents from the local government area. This shows specific sex differentials in favor of females.

Distribution of the age group of respondents (\% in parentheses)

$X=38 y r s ;$ Std \pm II.8yrs; Mo $=25 y r s$, Age range $=$ $15-74 y$ rs.

In Imo state, the respondents had a greater and more even spread from the ages of 19 to 59 years. 
The age range of the respondents were from $15-74$ years and the mean age is $X=33.8$ years. Also, the standard deviation is \pm 11 .8years, and the modal age is 25years. The age range of $35-39$ and $45-49$ provided the highest proportion (29.8\%) of respondents.

Distribution of respondents by specific marital status (\% in parenthesis)

The preponderance of the respondents in Imo State are either married, $(62 \%)$ or single (33.1\%). Slightly less than two third, (62\%) of the respondents are married; while about one-third, (33.1\%) are single. The respondents that are divorced, $(0.5 \%)$, widowed, $(3.9 \%)$ and separated, $(0.5 \%)$ are few.

\section{Awareness of human trafficking in Imo State}

Generally the respondents are aware and confirm the existence of human trafficking in the area. Indeed most of them (75\%) agree that they are aware of the practice. However, the study further enquired about awareness of specific forms of human trafficking like women and child trafficking.

Distribution of respondents by awareness of women/child trafficking (\% in Parenthesis)

The respondents from Imo state indicated high awareness $(71.5 \%)$ of the practice of women trafficking. They also presented similar indication on child trafficking but the indication is higher (89.3\%) than that of women trafficking. The interview with victims in Imo State also indicated that some victims were aware, but some especially the young and illiterate parents do not understand the concept and are not aware of child trafficking. For instance, some stated that you can give out a child to a relation or friend to either learn a trade, handwork or school but could not establish the link between this traditional practice and human trafficking. According to one participant from Ahiazu Mbaise, “... what we know here is that parents give their children to relatives to help them train or teach them trade..." Interestingly, another male participant gave a historic account of trafficking in Ehime Mbano area in the 1940's and 1950's. According to him;

“... when I went to Calabar in the 1940's, we were working, but those who took us to Calabar were eating the money. Then, the person that took people to towns usually collect all the wages, they eat all the money, we were up to five persons from my village, Umuaro..."(Community leader male 57yrs Imo State).

Another participant also stated that, “... when we travelled to Yoruba, specifically Akure from my village in Umunumo to cut timber or "Iged" we were two and some other people from Umuezealla. Before we got there, the person who took us to the place had collected our wage for one full year. It was only after the second year that we were paid something..."(Interview Male, 50yrs Imo State)

Yet another community leader in Imo state narrated how at about 1954 during the construction of ljebu-Benin -Lagos road and Ore bridge, “... one Mark brought three of his kinsmen to work for African Timber and Plywood (ATP) company at Okitikpukpa, and collected their salary for four years..."There are indications from these findings that human trafficking or vestiges of the practice has been in existence in Imo State even in the 1940's before the current global awareness.

Demographic and cultural factors associated with human trafficking

Characteristics of households in the communities in Imo State.

The Number of Children in Households in Imo State, a little less than two third, (62.8\%) of the respondents indicated that most households in the communities have between $5-10$ children, on the other hand, less than one-third (26.5\%) indicated between I - 4 children per household.. This outcome showed that households in the State record high number of children, indicating also that the families are marked by large family size. Therefore, the number of children by households in the communities is very significant. $\left(X^{2}=24.369\right.$, df $=$ $19, P<.182)$. The interview with victims in Imo State also confirmed that the lowest number of children in the household of the victims were six, (6) and the highest were eleven, (II).

Distribution of respondents by the reason for the number of children found in households in the community.

About two third of the respondents in Imo State identified culture and tradition (69.3\%) as the major reason for large number of children found in households. This is followed by ignorance (20.7\%). On the other hand, only a few respondents $(2.1 \%)$ related family planning to small family size. The factor of culture and tradition was also found to be significant $(P<.000 \mathrm{I})$ especially in relation to large family size in the area. Based on the above finding, it was important to further establish the specific aspect of the people's culture and tradition that has most effect on large children and large family size among households in the area. The result shows that two third of the respondents (69\%) identified the culture of "ewu-ukwu" (local language) which literally means 'goat for the bottom' a fertility rite for women. This cultural practice which includes the killing of a goat bestows special status and honor to women who 
have ten children and above in the area. Therefore every woman strives to attain this status, thereby giving rise to large number of children in households. Another reason for large number of children is the belief that children come from God (30\%) and so man should not interfere with the process. The interview participants also corroborated the concept of ewu-ukwu in Imo State, especially within Mbaise and Mbano area of the State. According to a participant, Women in this area regard child birth very seriously, they use it to proof their womanhood and look forward to achieving the ewu -ukwu status". One of the participant said "Child birth is mostly regarded as divine, so people give birth to children according to the will of God". Another interviewee said, "people in this area do not joke with the issue of child birth, children bring respect and honor to the family, they give their children names like, Nwabueze,Nwabugwu, Chinenyenwa, Chinaza and others" meaning Child is king, child is respect, God gives children, God answers.

Knowledge and characteristics of human traffickers

The study went further to find out the characteristics of the traffickers, especially their sex in other to ascertain whether they are mostly male or female.

\section{Distribution of respondents by the sex of traffickers.}

Table I represents the view of the respondents on whether the traffickers are mostly male or female. The table shows that majority (46\%) of the respondents identified females as the most likely traffickers. However, many of the respondents (44\%) also identified males as likely traffickers.

To further confirm the issue of sex and trafficking in the state, the hypothesis which states that females tend to participate as traffickers more than males was tested. The $X^{2}$ value of 41.259 indicates a difference between the observed proportion and what is expected by chance occurrence. To determine whether this difference is significant or not, it was established that the computed $X^{2}$ value at $41.25 \%$ is higher than the critical $X^{2}$ value at 10.827 . Therefore, the substantive hypothesis is upheld. It also shows that there is a significant difference $(P<.000 \mathrm{I})$ between the sex of traffickers in the state.

The study inquired about the reason the traffickers mostly give to convince possible victims of trafficking. It was found that the most reason is offer of good job locally or abroad (54\%) for women victims and offer of school or trade (46\%) for child trafficking. The study further carried out multiple regression analysis in other to know the predictive power of sex and other socio demographic characteristics on the awareness of tendency to traffic women and young girls through promise of good job. In this instance, the dependent variable is tendency to traffic women and young girls through promise of good job, and the independent variables are sex, marital status (married), economic activity, religion (Christians), education, age and income. The intention is to know the combined effect of sex and other socio demographic characteristics on the awareness of the tendency to traffic women and young girls through promise of good job, and also the specific effect of each of the social characteristics on the awareness of the tendency to traffic women and young girls. The result of the multiple regression analysis is presented on table 2 below.

Multiple regression analysis of the awareness of tendency to traffic women and young girls through promise of good job on sex and other social characteristics of respondents

Table 2 shows that the R-square which measures the variance between variables is 0.012 . This implies that $1.2 \%$ of variation in the awareness of the tendency to traffic women and young girls through promise of good job is explained by the joint effect of sex and other social characteristics contained in the model. However, this relationship is not statistically significant at $\mathrm{P}<0.153$.

On the relative effect of each of the variables in predicting the awareness of tendency to traffic women and young girls through promise of good job, the table shows that the regression coefficient for sex, marital status (married), economic activity, Christianity, education and age indicated positive association or relationship. The table showed that economic activity with a t-value of 2.0 ; education with a $t$-value of 1.9 , and sex with a t-value of 1.2 are the most important contributors in predicting the awareness of tendency to traffic women and young girls through promise of good jobs. Also, income indicated a negative or inverse relationship on the tendency to traffic women and young girls through promise of good job at a level of -0.037 . This implies that a unit change in the income of the respondent will bring about a decrease in the awareness of the tendency to traffic women and young girls through the promise of good job by 0.037 periods. In other words, high income has a low or negative predictive power while low income has a high or positive predictive power on the awareness of the tendency to traffic women and young girls through promise of good job. Therefore, promise of good jobs abroad by traffickers has negative effect on high income individuals, and positive effect on low income individuals. This relationship is significant at 0.3 levels. Also the positive relationship between education and 
the awareness of the tendency to traffic women and young girls through the promise of good job is significant at 0.055 levels.

We further considered the effect of sex and other socio demographic characteristics on the awareness of tendency to traffic women and young girls through promise of training in school or skill. This is important because respondents perceive this factor as the major reason the traffickers give to convince children or their parents. Therefore, the dependent variable is the awareness of tendency to traffic women and young girls through promise of training. The independent variables are sex and other social characteristics.

Multiple regression analysis of the awareness of tendency to traffic children and young girls through promise of school/trade on sex and other social characteristics of respondents.

Table 3 shows the value of the combined effects of the independent variables or $R^{2}$ value as 0.025 . This implies a $2.5 \%$ variation or unit change in awareness of tendency to traffic children and young girls through promise of training in school and skills as a result of the joint effect of sex and other social characteristics. This relationship is also statistically significant at $\mathrm{P}<0.003$ levels. The effect of the specific independent variables showed that the regression coefficient for sex, marital status (married), religion, (Christianity) and age indicated a positive association, while economic activity, education and income indicated a negative or inverse relationship with the awareness of tendency to traffic women and young girls through promise of training in school and skills.

\section{Characteristics of victims and people that are trafficked.}

The proceeding part of the study will focus on the victims of human trafficking. The study identified possible victims, examined the most likely gender of victims, the likely age groups, and whether the victims are aware that they will be trafficked before giving their consent.

Distribution of respondents by the gender that are victims of human trafficking

$\mathrm{X}^{2}=32.569 ; \mathrm{df}=2 ; \mathrm{P}<.0001$

The study found that in Imo state, over two third $(81 \%)$ of the respondents identified females as the most victims. The statistics $\left(X^{2}=32.569\right.$, df $=2$; $\mathrm{P}<.000 \mathrm{I})$ further indicated a significant difference between the gender of the victim and vulnerability to human trafficking.
Distribution of respondents by the age group of females that are victims of trafficking

The study also examined the age group of females that are victims of trafficking in Imo state. Generally, adolescent women between the ages of 16-25years are the most victims of human trafficking. The statistics $\left(X^{2}=64.855 ; \mathrm{df}=5, P<0.000 \mathrm{I}\right)$ also shows a significant difference in the opinion of the respondents as shown in the age groups. However, for child victims in Imo state, the most vulnerable age group is between, $6-15$ years. This is indicated by more than three-quarter (93.9\%) of the respondents in Imo state.

Characteristics of families that mostly give out children to others.

The study examined the various characteristics of the family like low-income, large number of children, father with no formal education and others and also whether the tradition and culture of the people supports giving out children to live with others.

Distribution of respondents by the characteristics of families that mostly give out their children to traffickers

Indications from the data shows that in Imo state, families with large number of children, father with no formal education, mother with no education and low income families are most likely to give out their children to traffickers. On the other hand, families with small number of children, father with formal education, are less likely to give out their children to traffickers. The factor of the father is very important because in Patrilineal societies as is the case in Imo state, fathers take most of the decisions in the families. However, in some cases of trafficking as found out in the study, the father figure may be absent, especially among single parents, widows or separated families whose children are also vulnerable. The hypothesis which states that there is a significant positive relationship between large family size and being victim of human trafficking was tested. The statistics $\left(X^{2}=27.777, \mathrm{df}=4, \mathrm{p}<0.00 \mathrm{I}\right)$ revealed a significant positive relationship between family size and being victim of human trafficking. Further the critical $X^{2}$ value which is 18.465 is less than the computed $X^{2}$ value of 27.777 . Therefore, we reject the null hypothesis, and uphold the substantive hypothesis.

The perception score as presented above also shows that in Imo State, the score range from three to ten. Also, $50 \%$ of the respondents in Imo State scored between six and eight. However, the median score for Imo State is seven. Therefore, there is no significant difference in the perception score on characteristics of families most likely to traffic 
children in Imo State. The study further carried out multiple regression analysis in other to know the effect of sex and other social characteristics of respondents on the tendency of giving out children to live with others. The dependent variable in table 3 is the tendency of giving out children to live with others and human trafficking, while the independent variables that makes up the model are, sex, marital status, (married), economic activity, religion, (Christian), education, age and income.

Multiple regression analysis of the tendency of giving out children to live with others, sex and other social characteristics

Table 4 shows that the R-square which measures the variation between the dependent variables and the independent variables is $3.1 \%$. This implies that $3.1 \%$ of variation in the tendency of giving out children to live with others is explained by the joint effect of the social characteristics contained in the model. Put differently, the combined effect of the social characteristics of sex, marital status, economic activity, religion, and others on the tendency of giving out children to live with others has an estimated variation of $3.1 \%$. Also, the level of probability at $\mathrm{P}<0.00$ I shows that there is a significant level of association between the tendency of giving out children to others and the joint effects of the social characteristics of respondents in the model. The relative effect of each of the variables to predicting the tendency of giving out children to live with others, shows that the regression co-efficient for sex is-0.022. This outcome indicates an inverse relationship between sex and the tendency of giving out children to live with others. In other words, a unit change in the sex of the respondents (female to male), will bring about a decrease in the tendency of giving out children to live with the others by 0.02 periods, and vis-versa. It also showed an inverse association between marital status (married to non married), economic activity, religion (Christian), and level of education; and the tendency of giving out children to live with others.

For instance, education with the highest negative relationship of -0.538 , indicates that a unit change in the level of education, from no education to education for example will lead to 0.53 decrease or less tendency of giving out children to live with others. This relationship is significant at 0.24 levels.

On the other hand, age and income indicated a positive association with the tendency of giving out children to live with others. The regression coefficient of income is associated with a positive relationship of 0.016 . This means that a unit change in the income of respondents will result in 0.016 unit change in the tendency to give out children to others, when the effect of other variables are controlled. This outcome is however, not statistically significant at $\mathrm{P}<0.72$ levels. This implies that the perceived association may be a result of sampling error. This is corroborated by the standard error of estimates of 0.044 , which shows a weak degree of predictability. However, the degree of predictability of economic activity at the level of $\mathrm{P}<0.000 \mathrm{I}$ is very strong and indicates the highest level of predictability.

\section{Discussion of findings}

A total sample of six hundred was chosen for this study (600). However after the distribution of the questionnaire instrument, five hundred and seventy (570) instruments were duly completed and returned. Therefore, 570 became our actual sample of respondents on whose perception most of the following discussions are based. This number amounts to a return rate of $95 \%$ which is much higher than the generally acceptable minimum of $70 \%$ for a study of this nature, (Monethe, Sullivan and Dejong, 2004), and In-Depth Interviews (IDI) were also conducted to revalidate and complement the findings of the survey instrument.

Socio-demographic characteristics of respondents The data from the study shows that female respondents are more than the males. This may be due to coincidence in instrument distribution, rather than a deliberate design. The age group of the respondents were mostly between 35 to 39 years and 45 to 49 years. Also, most of the respondents were married.

\section{Awareness of human trafficking}

Generally, the study established a high level of awareness of human trafficking (HT) in Imo State. Also a high awareness level was recorded for both women trafficking (WT)and child trafficking (CT) in the area. However, some of the ordinary traditional practices like giving out children to live, serve or learn trade from relatives or friends which is common in the area could not be related to human trafficking by community members.

This gap in awareness is very critical to the constant vulnerability of victims.

Studies conducted by African Network for the Protection and Prevention of Child Abuse and Neglect, ANPPCAN, (2000) and Hodges, (200I) also established the prevalence of child trafficking in Imo state. But this study further found that though most respondents are aware that you can give out a child to a relation or friend to either learn a trade, handwork or school, they could not establish the link between this traditional practice and human trafficking. This gap in awareness is critical to the 
constant vulnerability of victims, especially children. The study also found that in Imo state human trafficking may have been existing even in the 1940's and 1950's, especially among male youths. However, this is peculiar to internal trafficking.

Demographic and cultural factors of human trafficking characteristics of households in the community

The notion that there might be an association between the fertility behavior of a people and disposition to human trafficking as was captured in our research hypothesis two was confirmed. Consequently, it was established from the respondents in Imo state that households in communities have high number of children, $(5-10)$ an average fertility rate of $5 \%$. This outcome naturally leads to high family size. In Nigeria, this could pose a problem of inability to effectively take care of the children especially with the inherent harsh economic situation that leads to food insecurity and inability to meet basic needs like education, healthcare and shelter, (Barkindo and Lipede, 2007), thus positively disposing the children to human trafficking. The study further sought to find out the reason for this preference for large number of children in households. The finding was that in Imo state, culture and tradition of the people are the major reasons identified by respondents for large children in households. In other words, the culture of the people permits large families. To identify the specific aspect of the culture and tradition of the people that most influence high number of children in households, the study relied on FGD and interview discussions. It was found that there is the general belief that children come from God, but more than that, Imo state was found to have specific cultural and traditional practices that directly leads to high number of children in households.

In Imo state, it was established that AhiazuMbaise and Ehime-Mbano have specific culture and tradition that encourage and give impetus to large number of children. It is the tradition in these areas that women who give birth to ten children and above are bestowed the highest traditional status and honor among women in a fertility rite called 'Igbu ewu ukwu', marked by the killing of a fat goat to celebrate each woman. Therefore, every woman in these communities strives to attain this status by giving birth to so many children. Consequently, the harsh economic situation in Nigeria makes it so difficult for the family to effectively provide for the children, thus creating a condition of vulnerability. This finding has implications and indeed questions the effect of existing family planning and birth control measures in
Nigeria. An implication that require urgent attention in future family planning efforts.

\section{Knowledge and characteristics of human traffickers}

The study established that the first set of traffickers are mostly relations of the women and children, and friends of the family. Apparently most trafficking scenario begins with misplaced trust on those that are close to the victims. The culture of obedience and family, reinforce this reality. In the state, a child would hardly say no to the decision of the father, mother or elder siblings, and a relative is often considered family. This is also one of the factors established by Chi-yin chung (2006) in her study on the traditional Asian cultural and social values that make Asian girls especially vulnerable to human trafficking. Therefore, aggressive sensitization to educate the families on the reality and dangers of human trafficking should be pursued. The study further identified the most likely sex of the traffickers. It was found that females were mostly identified as traffickers though males also participate at specific stages of the network. This is critical in view of the fact that females are thought to be harmless and protective as mothers. Surprisingly, the reverse is the case with human trafficking. The implication of this for both policy and enforcement is that measures aimed at preventing and mitigating the effects of human trafficking should be first targeted at women.

Another useful finding in this study is what the traffickers tell the victims to get their consent. The most prominent reason is offer of good jobs for women trafficking and offer to send children to school or learn a trade for child trafficking. The implication of this finding for policy is that if jobs could be provided for the vulnerable age ( $15-25 \mathrm{yrs})$ and school guaranteed for the children, $(6-14 \mathrm{yrs})$, a large proportion of victims could be salvaged or prevented from being trafficked.

The multiple regression analysis on the awareness of tendency to traffic women and young girls through promise of good job on sex and other socio demographic characteristics of respondents further indicated that sex, marital status (married) economic activity, Christianity, education and age are positive contributors to predicting the awareness of tendency to traffic women and young girls through promise of good job, while income is a negative predictor. Also, the multiple regression analysis of the awareness of tendency to traffic women and young girls through promise of training on sex and other social characteristics of respondents showed that sex, marital status, religion (Christianity) and age are 
positive contributors, while economic activity, education and income are negative contributors.

\section{Characteristics of victims and people that are mostly trafficked}

The study established that females are the most victims of human trafficking. In other words females more than males are mostly victims of human trafficking in Imo state. So many reasons have been adduced by several scholars to explain why women and girls are more preferred than men as victims of trafficking. Ward (2005) related the preference for girls to the intricacy of the worldwide sex industry. According to her, a large percentage of clients in the sex industry seek prostitutes whose racial, ethnic, caste or national identities are different from their own and by importing and exploiting foreign prostitutes, traffickers are better able to meet demand criteria most of which are by men.

The study further examined the age group of females and children that are mostly victims of trafficking in the state. It was established that women between the ages of $16-25$ years are the most vulnerable to being trafficked. While for the children, the most vulnerable age group is between $6-15$ years. The preference for these age groups may be determined by demand specifications and the use to which the category of persons are put into. Most of the child victims are usually deployed into petty trading, hawking, child labor, and domestic exploitation. However, women within the identified age group seem to be most preferred by the clients. According to Ward (2005:90) a study conducted in 2003 by the International organization for migration (IOM) indicated that three quarters of the 185 clients surveyed expressed a preference for prostitutes under the age of 25 , and $22 \%$ preferred those 18 years of age or under. Giving further explanation, Ward also noted that sometimes clients who already have sexually transmitted infections may believe, according to the myth of the "virgin cure", that sex with a virgin will heal their disease. Bizarre as this may seem, it is not very far from the general preference of men for younger females who are perceived to be young, fresh, and better than older women.

\section{Characteristics of families that mostly give out their children to traffickers}

The study found that in Imo state, families with large number of children, father with no formal education, mother with no education, and low income families are most likely to give out their children to traffickers. On the other hand, it found that families with small number of children, father with formal education, are less likely to give out their children to traffickers. Evidently, families with large number of children will be under tremendous pressure to effectively provide for all the children. This task may not be easy with the harsh economic situation in Nigeria. Consequently, it may not be possible to put some of the children in school, provide the essentials for them and may be prone to being giving out to others who may be traffickers. Also father and mother with no formal education will make it difficult for the parents, to make informed decisions about the future of their children. They would hardly be able to unravel the deceit in the sweet talks of the potential traffickers; hence they are more prone, to giving out their children. In most cases, illiterate parents are also poor. Therefore, a combination of these two factors will predispose the children from these families more to being trafficked. Another important factor is low income families. Families with low income are less likely to meet up with family responsibilities and obligations. Therefore, children from these families would be more prone to be given out to others who may be potential traffickers.

The above result is corroborated by the regional study of International Program on the elimination of child Labor. According to this study, children are more at risk of being trafficked when they are members of a family with 5 or more children (ILO, 2000). The study which was on child victims showed that in Benin Republic, most of the children came from families with more than 5 children. In Cameroun, most of the victims were members of families with 6 to 9 children, while in Mali, most of the children came from families with an average of 7 to 8 children. The same study also confirmed that the education level of parents of trafficked children is generally low. Similar outcome was recorded in Benin Republic, Cameroun and Burkina Faso.

The multiple regression analysis of awareness of trafficking young children for hard labor indicated that families with large number of children are the most important contributor in predicting the awareness of trafficking young children for hard labor. The second most important contributor was families with more female children followed by families with low income. The multiple regression analysis of awareness of trafficking young women and girls for prostitution also showed that families with large number of children are the most important contributor.

Human trafficking and the realization of the Sustainable Development Goals (SDGs)

The existence of human trafficking globally and specifically in Nigeria constitutes a great challenge to the implementation and realization of the Sustainable Development Goals (SDGs). This challenge which is 
two prong first brings to the fore the existence of a global problem that needs urgent global attention. Secondly, it calls for urgent global action to eradicate the practice. Generally, 8 of the 17 SDG goals address the crime of human trafficking and its eradication. These are goals number I: No poverty; number 2: zero hunger; number 3: good health and well being; number 4: quality education; number 5 : gender equality; number 8: decent work and economic growth; number 10: reduced inequality and goal number 16: peace, justice and strong institutions. The various targets of these goals relates to aspects of the results of this study. Specifically, according to UNICEF (20I6), human trafficking was mentioned in the targets of three goals, 5,8 and 16 . This is an indication that nations and peoples around the World will approach this grave human right violation with a greater priority and attention.

For instance, goal 5 targets to achieve gender equality and to empower all women and girls. The result from this study indicated that women and girls are the most likely victims of human trafficking. The condition of vulnerability by women which makes them victims of human trafficking is largely a result of existing gender inequalities and less opportunity for women in societies (Crawford 2016; Hume and Sidun 2016). UNICEF (2016) also asserted that women and girls made up $70 \%$ of detected human trafficking victims between 2010 and 20I2. SDG goal number I emphatically declares 'No poverty', yet nearly 2.2 billion people and half of the World's population still live on less than \$2 per day, trapping them in abject poverty and creating vulnerability to human trafficking. This is the situation with Nigeria and most developing countries that are source countries for victims of human trafficking due to the high poverty rate and very low living standards (Shelley 2010; Crawford 2016). Consequently, goal 8 target 7 calls for all Nations to take immediate and effective measures to eradicate forced labor, end slavery and human trafficking.

Indeed, agenda 2030 and the Addis Ababa action agenda drew a clear line between combating the crime of human trafficking and sustainable development. The agenda focused attention on the impact of lack of sustainable development on a crime which disproportionately affects poor Countries and their vulnerable population groups, UNODC (2016). Therefore, SDG target 16.2 calls on all nations to end abuse, exploitation, trafficking and all forms of violence against women and children. These goals can only be achieved if nations work together to end this modern slavery of human trafficking.

\section{Conclusions}

The study established that some demographic and cultural factors are associated with the crime of human trafficking in Imo State. For instance sex and gender are associated with human trafficking. Females were identified to participate as traffickers more than the males. Also, females were found to be mostly victims of human trafficking than males. This result is the same for both women trafficking and child trafficking. Most households were found to have high number of children and this preference was found to be embedded in the culture of the people. Specifically, the practice of fertility rite for women called 'Igbu ewu ukwu'served as traditional impetus for families to have high number of children. Also families with large number of children, fathers with no formal education and low income families were found to most likely give out their children and young members to traffickers. The preference for large number of children in households is an indication of the low value attached to family planning in the area. The implications of this result for policy is that effective family planning measures should be promoted to target fewer number of children and discourage large number of children in families. There is a nexus between the global existence of human trafficking and the realization of the sustainable development goals, which is the reason eight of the seventeen goals address the crime of human trafficking. This study which established some of the critical push factors of human trafficking further fits into this connection as it contributes to better understanding of the phenomenon from a source country, Nigeria and thereby contributes to the call for global action by the SDGS to eradicate the crime.

The recommendation from this study is strong campaign against human trafficking targeting the link between offer of good jobs abroad and giving out children to others and human trafficking. The next is free education to children from poor families. This is important because if the children are in school, they will not be victims of child trafficking. Most children who are not in school are because parents cannot afford the cost; some are children of single parents or separated parents. So, free education will help put these children back to school. The legal frame work around human trafficking should also be strengthened to ensure proper prosecution and severe punishment for offenders. This is very necessary because if a trafficker is severely punished, it will serve as deterrence to other people not to engage in the practice of human trafficking. Finally, measures should be put in place to reduce the level of poverty and increase lively hood options and improved wellbeing for women in Imo state and Nigeria. At the moment, most Nigerians live below \$Idollar per day 
despite the wealth of the country. Relating the results to the theoretical framework, the routine activity theory explains the prevalence of human trafficking on the fact that the practice occur within hitherto ordinary normal activity and the convergence of vulnerable individuals, willing offenders and a conducive environment makes human trafficking to thrive.

\section{References}

African Network for the Prevention and Protection of Child Abuse and Neglect, ANPPCAN

2000. Study on Child Trafficking in Nigeria, Enugu Nigeria

Angeli, F. 2003. "Stop trafficking in human beings, together its possible" International

Conference: $21^{\text {st }}$ Century Slavery- The Human Rights Dimension to Trafficking in Human

Beings. Milano, May.

Aransiola, J.O and Zarowsky, C. 20I4. "Street children, human trafficking and human security

in Nigeria" African Population Studies, Vol. 27, No 2.

Babbie, E. 1992. Survey research methods. California: Wadsworth Publishers.

Bales, K. 2012. Disposable people: New slavery in the global economy. California: University of

California Press

Barkindo, B. and Lipede, A. (ed) 2006. "Human trafficking and economic crimes across

Nigeria's international borders" African Strategic and Peace Research Group. Ibadan: Spectrum

Books.

Bryant-Davis, T and Tummala-Narra, P. 2016. "Cultural oppression and human trafficking,

exploring the role of racism and ethnic bias" Women and Therapy Vol. 40 issue I-2

Crawford, M. 2016. International sex trafficking. Women and Therapy, Vol. 40

Chi-Ying Chung, R. 2006. Human trafficking for sexual exploitation: Psychological and cultural

impacts. Global Studies Review. www.globalitygmu.net/archives/960

Coomaraswany, R.2000. Report of the special raparteur on violence against women,

trafficking in women. Economic and Social Council 8 Geneva

Felson, M. 2002. Crime and Everyday Life $3^{\text {rd }}$ ed. Thousand Oaks CA: Pine Forge Press.

Gallagher, A.T. 2012. The international law of human trafficking. New York: Cambridge

University Press.

Hepburn, S and Simon, R. J. 20I3. Human trafficking around the World.

Hodges, A. (ed.) 200I. Children's and Women's Rights in Nigeria's: A wake up call. Abuja:

National Planning Commission and UNICEF, Nigeria.
Hume, D. L. and Sidun, N. M. 20/6. Human trafficking of women and girls: Characteristics,

commonalities and complexities. Women and Therapy. https://doi.org/I0.1080/02703 |49.2016

Immigration update, 2002. "International human trafficking" Immigration News Magazine,

Zone 'E' Owerri.

International Labour Organization/IPEC 2000. "Combating trafficking in children for labor exploitation in West and Central Africa" IRD Geneva.

Kara, S. 2017. Sex trafficking: Inside the business of modern slavery. New York: Columbia

University Press.

Karlson, J.O. 2003. Poverty and Trafficking in Human beings. Sweden: Edita Vastro Aros.

Lobasz, J. K. 20I2. "Victims, villains and the virtuous, constructing the problems of human

trafficking" University of Minnesota Conserrancy. Umn.edu/bitstream/handle/I I 299

Laczkoy, F and Gozdziak, K. 2005. "Data and research on human trafficking: A global survey.

International Office on Migration Vol.43

Machetto, A. 2005. Final document: International meeting of pastoral care for the liberation of

women of the street.Rome: Vatican City, 20-2I June.

Monette, D. R., Sullivan T. J., and Dejong C. R. 2004.

Applied Social Research: Tool for the

human services. $4^{\text {th }}$ ed.

National Agency for the Prohibition of Trafficking in

Persons NAPTIP, 2006. "Blazing the

trail in Africa" NAPTIP News Abuja: Vol. I No. I, Dec.

National Population Commission, NPC 2006. Nigeria. http://www.population.goving

Ngbani, A. N; Maliki, A. E and Asuquo, P.N. 2017. Demographic variables and perception of

human trafficking in the South-South zone of Nigeria. Studies in Home and Community Science,

vol 3 issue 2

Obikeze, D.S. 1986. Introductory Statistics for the Social Sciences. Enugu: Forth Dimension

Publishing Co.

Obikeze, D.S. 1990. Methods of Data Analysis in the Social and Behavioral Science.

Enugu: Auto-Century Publishing Company.

Pearson, E. 2003. Study on Trafficking in Women in

East Africa. Germany: Deutsche

Geseuschaftur Technisihe Zusammenarbett.

Peters, A.W. 20I5. Responding to human trafficking: Sex, gender and culture. The Law.

Philadelphia: University of Pennsylvania Press.

Pierpaolo, R. 2003. Criminal Organization, Prostitution and Territory. Italy Castel Volturno.

Prina, F.C. 2003. "Trade and exploitation of minors and young Nigerian women for prostitution in Italy". Turin: Research Report 
Schaefer, R.T; 2005. Sociology. Boston: McGraw-Hill. Sherman, L.W. Gartin, P.R. and Buerger, M.E. 1989. "Hotspots of predatory crime: Routine

activities and the Criminology

of place" Criminology 27:27-56.

UNODC,2016.Inter agency taskforce on financing for development. https://www.un.org/usa/ffd-

follow-up

UNODC, 2018. Toolkit to combat trafficking in persons. http://www.unodc.org.

United Nations International Children's Education Fund UNICEF, 2000. Child trafficking in

Nigeria: Analysis of Nigeria's response to the Libreville platform of action. Abuja Nigeria.

UNICEF Fact Sheet, 2002.Child Trafficking. Nigeria, June.

UNICEF USA, 2016. Sustainable Development Goals. https://www.unicefusa.org

UNICEF, 2000. Child trafficking in Nigeria: Analysis of Nigeria's response to the Libraville
The CNN Freedom Project. 2018. https://editioncnn,com/

United Nations Office on Drugs and Crime UNODC, 2005. Washington, June II.

platform of action, Abuja-Nigeria

United States Department of State (USDS) Report, 2004. Trafficking in Person Report Europe

and Euroasia, June 14.

httpn://www.state.gov/g/tip/r/s/t:prpt/2004/33192

htm. Retrieved: I I

June 2005.

Ward, J. 2005. Sex trafficking in women and girls. Broken bodies, broken dreams:

Violence Against Women Exposed. United Nations OCHA/IRIN Publication.

Zimmerman, $C$ and Kiss, L 20I7. Human trafficking and exploitation: A global health concern.

https://doi.org//0.137| 